\title{
EMPIRICAL ANALYSIS OF STOCK RETURNS AND VOLATILITY: EVIDENCE FROM ASIAN STOCK MARKETS
}

\author{
Nawaz AHMAD ${ }^{\mathrm{a}}$, Rizwan RAHEEM AHMED ${ }^{\mathrm{b}}$, \\ Jolita VVEINHARDT ${ }^{c}$, Dalia STREIMIKIENE ${ }^{c}$ \\ ${ }^{a}$ Department of Business Administration, Iqra University, Defence View, \\ Shaheed-e-Millat Road (Ext.), Karachi-75500, Pakistan \\ ${ }^{b}$ Department of Business Administration, Indus University, Block-17, \\ Gulshan, Karachi-75500, Pakistan \\ ${ }^{c}$ Institute of Sport Science and Innovations, Lithuanian Sports University, \\ Sporto g. 6, LT-44221 Kaunas, Lithuania
}

Recceived 28 September 2015; accepted 10 April 2016

\begin{abstract}
The objective of this research isto measure and examine volatilities among important stock markets of Asia and to ascertain a causal relation between volatility and stock returns. For this purpose six markets KSE100 (Karachi, Pakistan), BSE Sensex (Mumbai, India), NIKKEI 225 (Tokyo, Japan), Hang Seng (Hong Kong), Shanghai Stock Exchange (SSE) (Shanghai, China) and KOSPI (Seoul, South Korea) were considered. Stock market indices comprise of daily data from the period January 2002 to December 2009. The graphical representation of time series shows the preliminary examination of stock behaviors. The analysis shows the high correlation and heteroskedastic trend (volatility) among the stock markets in selected time period. After preliminary analysis the formal descriptive method of mean, standard deviation and coefficient of variation have been applied for measuring and ranking purposes. The results show that KOSPI has the highest average annual return of $12.67 \%$ and followed by BSE with $11.61 \%$, whereas, KSE 100 has the least annual average returns of $9.31 \%$. The highest volatility coefficient of 3.097 has been observed in Hang Seng (Hong Kong) followed by 2.87 in Nikkei (Tokyo). However, the KSE 100 observed the lowest volatility coefficient of 2.078. Bartlett's test is applied for the inferential analysis to investigate whether the equality of volatility is the same in each market return. Finally, $\operatorname{GARCH}(1,1)$ model is applied which concludes a significant ARCH (1) and GARCH (1) effects and confirms all markets' returns are statistically significant since $\mathrm{p}<0.01$ and their Long Run Average Variances (LRAV) range from $1.52 \%$ to $2.54 \%$ for KSE100 Index and Shanghai Stock Exchange respectively.
\end{abstract}

Keywords: ARCH, GARCH, volatility, stock returns, Asian stock markets, LRAV, trailing variance.

JEL classification: C32, G12, G15.

Corresponding author Dalia Streimikiene

E-mail:dalia@mail.lei.lt 


\section{Introduction}

For developed stock markets, there is a long queue of empirical tests of return and volatility behavior. As far as developing and emerging markets are concerned, focus has begun for the last two to three decades as the concept of globalization has emerged, which brought integration in the world economies and specifically speaking in financial markets. Such globalization and integration in financial markets brought more investment opportunities for investors across the globe. Now one may enjoy even more diversified investment portfolio. Yet, rigorous empirical studies are required to examine risk, returns, volatility, efficiency, and other characteristics for the emerging stock markets so that investors and policy makers get benefitted. Singhania and Anchalia (2013), investigated the increase in trade volume between Asia and rest of the World, and concluded Asian markets have acquired prime locus within the World financial markets. Hence, it is important to carry out further researches in order to understand the definite behavior of Asian markets. The more so as the markets of this range react differently to changes, they are not equally integrated, what is highlighted by crises (Singhania, Anchalia 2013; Rajwani, Mukherjee 2013; Seth, Sharma 2015).

The financial market faces fluctuations by sort of any news, which contains different events, which may have any impact on stock market such as economic, business, or political events, which may cause a broad variation in stocks. However, it is considered as a normal behavior on the global stock market. An investor keeps on observing these events prior making any investment decisions. Occasionally market shows unpredictable movements, which are not according to the information given to the markets, thus, create Chaos in a market and irrational exuberance takes over financial fairness.

The rapid and regular changes in political and economic dimensions gained a particular attention to study the development and distributions of stock returns in emerging stock markets. These changes are happening in a great extent and direction in these countries, which are not normally taking place in developed markets. Schwert (1990) concluded that advancement in information and communication technology provided ease to get relevant information and also offered liquidity to investors in equity markets around the globe. This phenomenon has led two significant revolutions. First, investors have an access of rapid information; therefore, they gain better returns. Second, this relevant information is now disseminated even more quickly, thus, returns in stock prices are also secured. Hence, volatility could be a representative of a stock market with greater liquidity. Otherwise, if equity markets observe higher volatility, investors become more uncertain which may negatively affect stock market activities.

For instance regarding volatility behavior, Lee and Ki (1991), Claessens et al. (1995, 1998), Bekaert (1995), Bekaert and Harvey (1995, 1997), Choudhry (1996), Kim and Singal (2000), and Fama (1965) have found that the empirical data for stock market (stock prices or stock returns) exhibit leptokurtic trend and fat tails compared with normal distribution. Equity markets perform an efficient tool for distribution of wealth to its highest value operators. These stock markets also provide help to enhance investments and savings that are imperative for economic growth. 
However, Reisman (1999) concluded that stock prices are directly impacted by increase in money supply given that such increase in money supply channelized to stock market only and not invested anywhere else in the economy. If such increase in money supply channelized across the economy and causes increase in the general price level, the impact on the stock market is other way around. This is because the effect of inflation, which actively reduces capital formation. Today, investment in stock market has become more risk-taking because of its speculator behavior.

According to Wagner (2007) when stock markets demonstrate higher volatility, it creates panic to investors, then value of overall stocks' portfolios sadistically decline. This is evident that stock markets observe an economic cycle, which has boom, followed by recession and crashes and then markets reorganize and start gaining investors' confidence and become the part of revival phase followed by boom. Several research studies have been conducted in recent years, which examined the Asian stock markets behavior. Chen (2015), who analyzed the Chinese market, and concluded a positive and statistically significant risk return in SSE stocks, whereas, he further revealed that conditional mean of equity return is inversely related to the conditional variance in SSE stocks. The evaluation of the impact of the financial crisis revealed that there was a positive impact on volatility of stock returns in case of Japanese, Chinese and Indian stock markets, however, in case of Hong Kong equity market, it had no impact on the volatility (Singhania, Anchalia 2013). According to Inoguchi (2014) some studies have argued that the 2007-2009 global financial crisis affected domestic banks less in East Asia, even though the supporting evidence is rather limited. It was also found that the developed and developing markets, to which Pakistan is assigned, react to external news differently. For example the emerging markets of Asia have countered stronger in responses and extend of the reaction to the US news as compared to the Asian developed markets (Nguyen, Ngo 2014). However, most of the studies focus relatively on a small period of time.

Objective of the research. The aim of this research study is to follow a well-known theoretical framework of risk and returns association in six Asian stock markets followed by the presence of ARCH and GARCH effects. Moreover, whether these markets follow mean reversion or not, if so, slow or fast because it helps in forecasting future volatility and returns.

Research statement. This research is performed to study and measure the impact of volatility in six major emerging stock markets of Asia and also to rank these volatilities, and finally to ascertain an association through stochastic framework of analysis between equity returns and volatility.

\section{Literature Review}

According to Investopedia.com, volatility is defined as, the measure of spread about the mean return of stock. Standard deviation - the descriptive statistics tool is normally used for volatility computation. It permits an investor to evaluate how firmly equity return is grouped around an average return. A small standard deviation would refer to lower volatility that is the price is firmly huddled together. On the contrary, a large standard deviation 
(SD) refers to higher volatility that is the price is spread apart. In case of stock prices, larger standard deviation implies to the larger spread of stock returns and the investment in that securities become more risky. According to the modern stock portfolio theory, volatility creates risk, which is connected to the degree of spread of stock return around the mean. If the dispersion is higher from the mean, the risk is more in investment.

Empirical researches have been showing a great interest regarding forces that cause fluctuations in stock markets and stock returns, according to Investopedia, volatility is described as "it is the amount of insecurity or risk around the extend of variations in a stock's value. A high volatility implies that a security's value can potentially be spread out over a larger range of values. Thus, the price of the security could swing considerably over a short time period in either direction. Alternatively, a lower volatility would lead to fewer fluctuations in a security's value over a period of time". A study conducted by Schwert (1989) suggested that it is very difficult to identify the sources, which contribute to volatility, and this estimator built on the estimation methods. Davidian and Carroll (1987) have suggested it and also incorporated the similar characteristics of autoregressive conditional heteroskedasticity (ARCH) estimator of Engle (1982). Though, volatility modeling and forecasting have confirmed to be greatly beneficial in finance, the reason behind Engle's (1982) original ARCH model was to deliver a tool for estimating the dynamics of inflation insecurity. Okičić (2015) investigated the behavior of stock returns of Central and Eastern Europe (CEE) stock markets with emphasis on the association between conditional volatility and stock returns. Findings of the study provide confirmatory evidence that ARIMA and GARCH processes provide parsimonious approximations of mean and volatility dynamics in the case of CEE stock markets. There is overwhelming confirmation corroborating the presence of a leverage effect, it means that the amount of negative shocks escalate volatility more as compared to the positive shocks do. Raza et al. (2015) have applied a number of GARCH family models for the valuation and foreseeing the volatility of KSE100 Index stock returns. Eleven years daily closing prices starting from 3rd of June 2002 to 31st of May 2013, total number of 2724 observations of KSE100 index have been selected and analyzed. To model the conditional mean equation for KSE100 index stock returns, they have used ARMA specifications. They have attempted to locate the best-fitted GARCH model. For estimation and forecast of volatility they have used symmetric and asymmetric GARCH family models like GARCH, EGARCH, APARCH, and GJR-GARCH models. They have analyzed that the best-fitted volatility model is $\mathrm{GARCH}(1,1)$ with student's t-distribution and best prediction volatility model is GARCH $(1,1)$ with GED, similarly second best volatility forecasting model is EGARCH $(1,1)$ with GED. Balli et al. (2015) have examined the spillover effects of stock returns and volatility from developed markets to emerging and frontier markets. Thus, they took Europe, Japan, and US as developed markets, while 20 emerging and frontier markets from Asia, Middle East and North Africa (MENA) regions have been selected. For this purpose they have selected the stock markets of Saudi Arabia, Pakistan, India, South Korea, Jordan, Vietnam, Egypt, Bangladesh, Malaysia, Indonesia, Morocco, Philippines, United Arab Emirates, Oman, Singapore, Kuwait, Bahrain, Tunisia, Qatar, and Thailand. They have confirmed the spillover effects of stock returns and volatility from developed markets to emerging and frontier markets. They have also studied 
the aggregate effects of overall returns and volatilities spread and spillovers of developed markets. For the study of this aggregate spillover and volatility they incorporated univariate AR-GARCH models. The results show that US markets have dominance over other developed markets, results of variance ratios confirm this dominance of US stock markets across all other emerging and frontier markets also, however, the extend of variation is different among these markets. They further concluded some other factors, such as: portfolio investment, volume of investment and distance are also contributing factors in order to explain these spillover effects.

Several recent researches also studied the subject and application of volatility modeling and forecasting in stock returns. Rich and Tracy (2004) examined the relationship between inflation uncertainty and different factors of labour market; and, this was also linked to Engle's (1982) previous research study. Though, Harvey et al. (1994) explored and argued that because of multivariate variations of GARCH family models, they are not suitable to employ for estimation and explanation. These models have large number of parameters and needs to enforce limitations, and suggested model volatility as undetected element. On the other hand, GARCH family models are quite widely used till now (e.g., Galbraith et al. 2015; Bentes 2015; Johnk, Soydemir 2015; Andreou, Werker 2015; etc.). Salinger's study (1992) discusses the appropriate methodology for calculating the impact of events on the value of the shares of the company. This study concludes that if there are dividends during an event, cumulative abnormal returns do not measure the impact of events on the value of the company. Thus, the study recommends considering pre event parameters in order to compute returns irrespective of any alteration in the parameters because of the event and goodness of fit of estimates will improve, if other than return factors are controlled. Wealth effect of mergers and acquisitions, and the price impact of decisions on the financing of the company, these are important examples. This results that abnormal returns are positive, and enormous against the abnormal returns, which are close to zero for acquirer.

According to Jarrell and Poulsen (1989) there were 663 takeovers have been taken place from 1960 to 1985 in which shareholders had received more than 20 percent returns from stocks, while acquirer of these companies got an anomalous yield close to zero. Another study conducted by Jensen and Ruback (1983) also studied the mergers and acquisition development. Meghir and Pistaferri (2004) examined and concluded the robust evidence of time-based variance dynamics having measured nine conditional variances of income shocks at micro level. Ramirez and Fadiga (2003) examined that the US wheat, soybean, and sorghum prices observe asymmetric patterns of volatility. Granger et al. (1989) suggested methods for involving time-varying volatility into interval forecast, whereas, Christoffersen and Diebold (2006) suggested methodology for financial applications probability forecasting. In conventional observed literature of finance that is very much consistent with this research study, attempted to measure volatilities for diverse time periods and tried to discover evident associations with distinctive variables. For instance, Officer (1973) attempted to measure annual volatilities based on monthly returns on a stock index, on the other hand French et al. (1987), and Merton (1980) tried to calculate monthly volatilities based on daily returns on stock index. Schwert (1998), established daily stock market volatilities considering 15-minute returns. Whereas, considering time frame, Taylor and 
$\mathrm{Xu}$ (1997) and Andersen et al. (2001) incorporated 5-minute returns in order to measure daily exchange rate volatilities. Yu (2002) considered nine different models that substitute each other in order to predict stock prices' volatility and judged the relative performance of such models. He used the data, which covers topmost 40 stocks of NZSE40, allocated weights through market capitalization. The sample time frame is from 1st January 1980 to 31st December 1998, which has 4741 observations of daily returns.

These models consist of both simple models like smoothening and random walk models and complex models like ARCH and SV models. In order to evaluate forecasting accuracy, four measures are used and main results are:

(i) The stochastic model, with reference to performance, proves the best among the models;

(ii) Performance of ARCH type models depends on its lag order. Among numerous ARCH types, the model GARCH $(3,2)$ is the most appropriate model and also sensitive to the selection of valuation method;

(iii) On the contrary, regression and exponentially weighted moving average models is not good performer as per any assessment measure.

Engle and Lee (1999), studied the twelve largest stock markets of the World and explored the association between markets volatility and equity returns from the time period of January 1980 to December 2001. The findings of the research were consistent with the previous researches in which anticipated association between stock return and volatility are sensitive. The results have been measured through parametric exponential GARCH-M, and found ten markets are positive in relation of returns and volatility but statistically not much significant. But at the same time by using flexible semi-parametric order of conditional variance, they estimated a negative relationship between stock returns and volatilities in most of the stock markets.

Batra (2003) investigated the variation in time for Indian stock markets' volatilities. He has taken a time period from 1979 to 2003 and incorporated asymmetric GARCH model with structural changes. He concluded the unexpected shifts in the equity volatility and also identified the reasons for these abrupt shifts in volatility. He studied the different stock surges in Indian stock markets in order to study the bearish and bullish trends and concluded a bigger volatility in given time period. Shin (2005) attempted to investigate the association between risk and return for several numbers of emerging markets. This study contributes a significant association between volatility and returns in emerging capital markets by following non-parametric conditional variance modeling. In this regard, GARCH, parametric as well as semi parametric model are used for estimation and inferences in the said study. The data is obtained from IFC - International Finance Corporation, one of the emerging market databases for 14 emerging stock markets that are relatively well established. Geographically speaking, there are a couple of European emerging markets i.e. Greece and Turkey. Six markets belong to Latin America, and these are: Venezuela, Mexico, Argentina, Colombia, Chile, and Brazil. Whereas, six markets belong to Asia, namely: Malaysia, Korea, Thailand, Taiwan, India, and Philippines. The sample tenure is from January 1989 to May 2003. This study investigates the impacts of 1987 stock market crash (also referred as black Monday) on the global emerging markets following GARCH 
model as Choudhry (1996) followed who studied the impact of 1987 stock market crash using monthly data from Jan 1976 to August 1994.

Chaboud et al. (2008) investigated the relationship of foreign exchange and US security returns without soiling of their combined volatilities with microstructure innovations. They found one could sample foreign exchange returns as in one sample as often as once every 15-20 seconds without soiling volatility approximations. Whereas, US treasury bonds may be sampled as often as 2-3 minutes on days in absence of US macroeconomic declaration; and as often as every 40 second on the days of announcement. By using simple Kernel evaluator, they experienced increase in frequencies' up to once every 2-5 seconds for foreign exchange returns and once every 30-40 seconds for US Treasury bond returns. It is important to note that these sampling frequencies are higher in many folds as compared to the recommended in literature on recognized volatility in stock markets. In this research the higher sampling frequencies for foreign exchange and US T-bonds yield reflected the greater depth and liquidity of these developed equity markets. Amaert and Hyfte (2005) discussed the issue of long horizon mean reversion. They considered Brussels Stock Exchange indices for the period of 1832-1914. They used historicalequity returns and diverse portfolios volume in order to analyze the mean reversion behavior in equity returns. Their findings show that there is down to earth or almost negligible mean reverting phenomenon presented in equity returns. According to Shiller (1981), Shiller and Perron (1985), Summers (1986), if equity returns display gradually mean reverting pattern, former "weak form" checks, related with historical stock return orders, dearth of statistical influence in rejecting the null hypothesis of market efficiency in comparison of alternative hypothesis. Summers (1986), Shiller and Perron (1985) have proposed "fads" model because of this model prices can deviate significantly from normal anticipations to fundamental values. These estimation errors may significantly affect projected equity prices, but this is for short-term and not rises for indefinite time period. The equity prices reverted back after certain time period because of market correction, and this is known as first order autoregressive price process as discussed by Summers (1986) and Shiller and Perron (1985).

\section{Hypotheses:}

$\mathrm{H}_{1}$ : Markets' volatility and returns are positively associated;

$\mathrm{H}_{2}$ : All market returns have equal Volatility;

$\mathrm{H}_{3}$ : Market returns have ARCH effects;

$\mathrm{H}_{4}$ : Market returns have GARCH effects;

$\mathrm{H}_{5}$ : Market returns observe Mean Reversion.

\section{Methodology}

We have selected major emerging stock markets of Asia to test volatility among them, we have taken KSE100 Index (Karachi, Pakistan), BSE Sensex Index (Mumbai, India), NIKKEI 225 Index (Tokyo-Japan), HANG SENG Index (Hong Kong), SHANGHAI Stock Exchange (Shanghai, China), and KOSPI Index (Seoul, South Korea). The secondary data has been extracted from the website of Yahoo Finance and KSE100 index for stock prices, for this 
purpose daily data has been taken from January 2002 to December 2009. For findings and data results, specialized packages Eviews and SPSS have been used for computations and to perform this study.

Models. The graphical representation of time series shows the preliminary examination of stock behaviors and the trend of each of the stock markets. Log returns for each of the stock markets are to be modeled, followed by correlations ( $r$ ), standard deviations $(\sigma)$ and coefficient of variations (CV). Correlation is used for interdependence between two stock market's returns. After preliminary analysis the formal descriptive method of mean, standard deviation and coefficient of variation have been applied for measuring and ranking purposes. It is also important to note that standard deviation is used for calculating the spread around the mean for every stock market data in a taken time period. This spread is particularly known as volatility and CV as a relative measure of volatility. Bartlett's tool was also the component of descriptive analysis and used for further validation - an inferential analysis used to test the null hypothesis for the equality of all 33 data sets variances in comparison of alternative hypothesis, which states that at least one pair of variance is not equal to the rest of pairs. Furthermore, General Autoregressive Conditional Heteroskedasticity i.e. GARCH $(1,1)$ Model is applied which is an econometric model used to compute volatility.

Descriptive. Stock returns for all six stock markets are computed by taking the natural $\log$. The mathematical equation for log returns can be expressed as follows:

$$
R_{t}=\ln \left(I_{t} / I_{t-1}\right)
$$

where: $R_{t}=$ Stock returns at time " $t$ "; $I_{t}=$ Stock market index at time " $t$ "; $I_{t-1}=$ Stock market index at $1^{\text {st }}$ lag of time " $t$ ".

For descriptive analysis of stock returns, Karl Pearson correlation analysis is carried out to compute interdependence among all pairs of stock returns:

$$
r=\frac{n \sum_{i=j=1}^{n} x_{i} y_{j}-\sum_{i=1}^{n} x_{i} \sum_{j=1}^{n} y_{j}}{\sqrt{n \sum_{i=1}^{n} x_{i}^{2}-\left(\sum_{i=1}^{n} x_{i}\right)^{2}}} \cdot \frac{1}{\sqrt{n \sum_{j=1}^{n} y_{i}^{2}-\left(\sum_{j=1}^{n} y_{j}\right)^{2}}},
$$

where: $r$ = Correlation coefficient; $x, y=$ Two stock returns; $n=$ No. of observations.

Standard Deviation is used as descriptive statistics' tool to modal volatility, i.e. average spread about the mean stock returns for the data tenure:

$$
s=\sqrt{\frac{\sum_{i=1}^{n}\left(x_{i}-\bar{x}\right)^{2}}{n-1}},
$$

where: $s=$ Sample standard deviation; $n=$ No. of observations; $x_{i}=\mathrm{I}^{\text {th }}$ observation; $\bar{x}=$ Sample average.

Standard deviation is used for calculating the spread around the mean for every stock market data in a stated time period. This spread is particularly known as volatility and CV 
as a relative measure of volatility for stock returns of each market. Standard deviation and coefficient of variation have also been applied for measuring and ranking purposes, and can be measured through following equation:

$$
\mathrm{CV}=\frac{\delta}{\bar{X}} \cdot 100
$$

where: $C V=$ Coefficient of Variation; $\delta=$ Standard Deviation; $\bar{X}=$ Mean.

Bartlett's Statistic: Bartlett's (1937) test has been employed in order to run inferential analysis, and Snedecor and Cochran have also applied it in 1989. The application of Bartlett's test is useful in order to check the equality of variances in $\mathrm{k}$ number of data sets. Equality of variances across the data sets is known as homogeneity of variances, analysis of variance (ANOVA) test also assumes the same notion of equality of variances across the groups, and Bartlett's test is the apparatus to confirm this assumption. The Bartlett's test also checks the normality of the data, which is based on statistics whose sampling distribution provides precise critical values if the size of samples are equal. These precise critical values of equal sizes can also be applied to provide extremely perfect combination to the critical values for unequal sample sizes also:

$$
\begin{aligned}
& \mathrm{H}_{0}: \delta_{1}=\delta_{2}=\ldots=\delta_{k}, \\
& \mathrm{H}_{a}: \delta_{i} \neq \delta_{j} . \text { For at least one pair }(i, j) .
\end{aligned}
$$

Stochastic volatility. In this part we discuss about some generalized class of models, which known as Stochastic Volatility (SV) models. In broaden term SV models basically permit the development of conditional variance process for stochastic component in the time series, for instance, GARCH models are known to be SV models. For precise and expressive classification we implement here the contrast ARCH category, which are known as real SV models. The latter explicitly comprises on unnoticed (non-measureable) shocks to the yield variance, which is the depiction of volatility dynamics. Thus, in this way variance process turns out to be integrally covert despite provision of all current and past evidences and faultless information regarding data creating process, and nobody claims about the precise value of existing volatility condition.

The procedural repercussion is that the volatility process could not be detectable in respect of distinct past knowledge. Thus, the evaluation of volatility state at day " $t$ " varies as concurrent or future info from days $t+j$, where $j>0$, is included into the analysis. This viewpoint condenses inference of covert factors from the past unique statistics (filtering) and from all accessible, plus future valuable data (smoothing). In comparison, GARCH models consider the conditional variance as assumed past information, as discussed earlier it usually employs (quasi) maximum likelihood procedures for inference, hence, smoothing does not have any function in this situation. In spite of all these dissimilarities, these two model classes are meticulously interrelated and supported to each other. In reality, from a practical point of view for forecasting purposes, it is very hard to differentiate the effectiveness of SV and ARCH models. Both SV and ARCH are the best for volatility forecasting for any practitioner. 
Furthermore, with the development of realized volatility concept, and allied use of intraday statistics for volatility assessment is innately connected to the continuous-time SV framework in the field of financial economics.

Engle (1982) had introduced ARCH process as a method to measure variations in conditional variance around different time periods. The variance is modeled as a linear pattern of squared errors of past for any specific lag in ARCH model. The sequential association in volatilities is modeled by letting conditional variance of error terms in ARCH (p) model, but it varies on the trailing value of the squared error:

$$
\begin{aligned}
& \varepsilon_{t} \mid \Psi_{t} \approx N\left(0, \sigma_{t}^{2}\right), \\
& \sigma_{t}^{2}=\operatorname{var}\left(\varepsilon_{t} \mid \Psi_{t-1}\right)=\beta_{0}+\beta_{1} \varepsilon_{t-1}^{2} .
\end{aligned}
$$

In above equation, $\psi_{t-1}$ is known as the information set presented at first lag of time period.

The ARCH models offered a framework of analysis, and ARCH family also develops time series models to measure the volatility. Despite many utilities, ARCH models have several limitations and problems such as:

i) The likelihood ratio test has chosen to be used for the execution of number of lags (q) and the squared residuals have been made part of the model.

ii) The squared error and its related number of lags that has inherited utility to capture dependence in the conditional variance might be varying large and which may cause larger conditional variance in the model, thus may not be parsimonious. In order avoid this perplexing problem Engle (1982) has outwitted it by laid down an arbitrary linearly declining lag length on an ARCH (4).

iii) Making other things identical, the conditional variance equation; also carry more parameters; some of them may have estimated values in negative. Thus non-negativity constraint may be averted.

To surmount these identical boundaries, GARCH model came into existence. This model carries inbuilt artificial constraints, which has capability to treat the non-negative conditions. The said model (GARCH) was solely developed by Bollerslev (1986). The GARCH model has two distributed lags which are used to explain variance; one is attributed to capture the frequency effects, whereas the second is dedicated to capture the variance in lagged values itself, so that long term effects can be identified:

$$
\operatorname{var}\left(\varepsilon_{t} \mid \psi_{t-1}\right)=\text { conditional variance, }
$$

where $\psi_{t-1}$ refers to the information accessible at first lag time.

For GARCH (p, q):

$$
\sigma_{t}^{2}=\omega+\sum_{i=1}^{q} \alpha_{i} \varepsilon_{t-i}^{2}+\sum_{j=1}^{p} \beta_{i} \sigma_{t-j}^{2},
$$

where: $\omega, \alpha, \beta=$ Coefficients; $\varepsilon_{t-1}^{2}=1^{\text {st }}$ lag of Square returns $(\mathrm{ARCH}(1)) ; \sigma_{t-1}^{2}=$ Trailing variance (GARCH (1)).

In the GARCH $(1,1)$ model, the anticipated variance in any data set is the composition of both long run variance and anticipated variance for the preceding period, which is further adjusted by taking into account the size of observed shock of preceding period. 
The estimates for financial returns in the GARCH model, both sum of coefficients of lagged squared returns and trailing conditional variance too much near to one. This evidences the high amount of persistence of shocks to the conditional variance and the existence of fairly extended memory nevertheless being smaller than one is yet mean reverting. More simply, even though volatility consumes fair bit of time, however, it eventually returns back to the originality, i.e. mean level of volatility. This manifest that the existing information does not influence on long run forecast. The rich amount of literature on SV models is available and still on increasing pace, thus the surveys are available on the subject, for example, Ghysels et al. (1996) and Shephard (1995). Hence, we have focused on producing an overview of identical approaches with special emphasis on volatility forecast and inferential techniques. Long run average variance is $\sqrt{\omega / 1-\alpha-\beta}$ which is only applicable when $\alpha+\beta<1$ and $\alpha>0, \beta>0$, and $\omega>0$.

\section{Estimations and results}

The results of this paper have been presented into four phases. In first phase, graphical presentation of time series based on historic data is presented. The descriptive statistics of stock returns including coefficient of variation followed by correlation is given in second phase of the results. Inferential analysis is conducted in third phase for variance equality. In last phase, econometric model confirmed the results of descriptive and inferential analysis.

Time series graph. The graph of Figure 1 shows the historic time series data for the indices of stock markets. The said result is plotted in line chart (Fig. 1). The fluctuations in

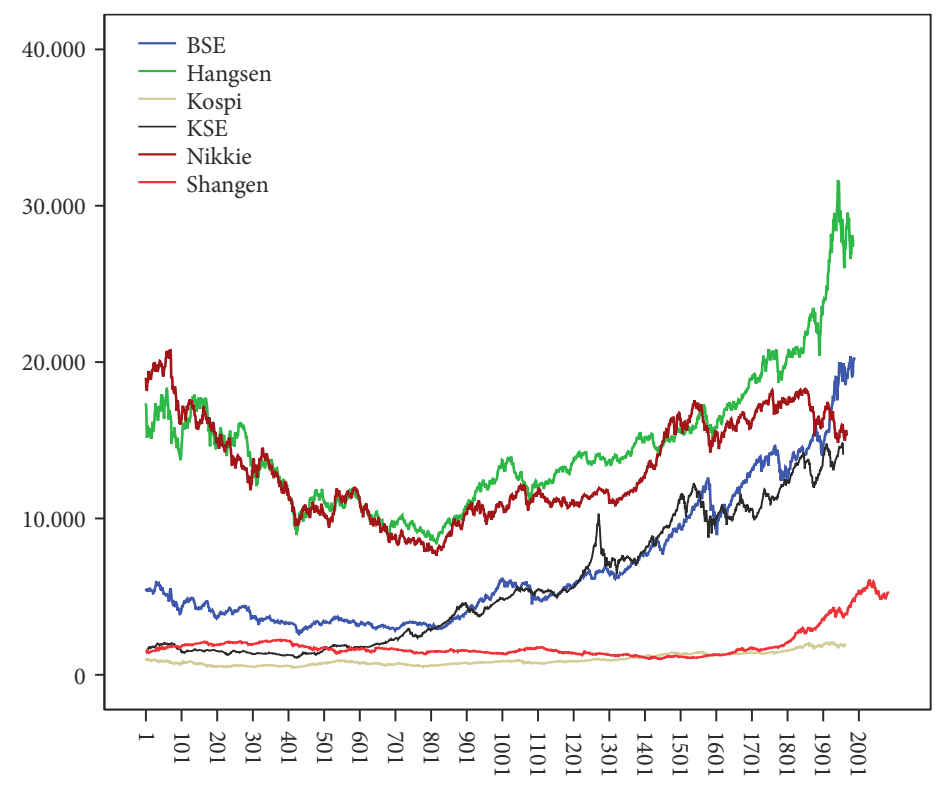

Fig. 1. Historic time series Source: authors' estimation 
data graph shows the uneven and spread and dispersion of data. It is also analyzed from the graph that only two stock markets, such as: Hang Seng and Nikkei225 have more than 5000 indices, while rest of the equity markets are below 5000 indices at the start of the data time period. It is also noted from the graph that all the stock markets have vibrant association among them. Nikkei225 and Hang Seng indices are almost touching to one another and at the end they get separated, and the same trend is followed by the KSE100 and BSE Sensex indices. If we observed the pattern of each stock market at the end period, it showed a declining trend, which is the depiction of huge loses and breakdown of investment in every stock market. However, this trend has shown in Q2 and Q3 of 2008, but in fact the reason of this financial crunch or breakdown has been started well before that period.

Descriptive analysis. Saleem (2007) has calculated the equity returns by using the natural $\log$ of the ratio of stock market index as: $\mathrm{SP}_{(\mathrm{t})}$ are the returns of KSE100 index for the daytime " $\mathrm{t}$ " and $\mathrm{C}_{\mathrm{t}}$ and $\mathrm{C}_{\mathrm{t}-1}$ are the closing and opening points of stock prices for the daytime " $\mathrm{t}$ " and " $\mathrm{t}-1$ " are closing and opening daytimes respectively. When stock returns are calculated they are in negative if stock index at time " $\mathrm{t}$ " is lesser than that of stock return at time " $t-1$ ", so in order to avoid these negative signs with returns, a square transformation has been followed to avoid negative signs. As shown in Table 1, KOSPI has the highest average return of $0.0351 \%$, and then BSE Sensex $0.0322 \%$, while KSE100 has the least returns of $0.0258 \%$.

The graphical representation also shown the volatility of each market and Table 1 shows the calculation of different statistics, which is obtained from descriptive statistics method. According to the Table 1, every equity market has a dispersion or spread around its average squared returns that is depicted through standard deviation. Thus, the volatility of every stock market could be equated with any other stock market along with amount and quantum of an equity market. The Table 1 also shown the maximum volatility coefficient of 3.097, which has been observed in Hang Seng, followed by 2.87 in Nikkei. The KSE100 has the lowest volatility coefficient of 2.078, and good for KSE100 despite the fact that Pakistan has been facing law and order, political instability, and war against terrorism, and many other events, which adversely affect stock market.

Table 1. Descriptive analysis

\begin{tabular}{lccccc}
\hline & $\mathrm{N}$ & Mean & Std. Deviation & $\mathrm{CV}$ & Rank \\
\hline Sq. BSE & 2453 & 0.00032252 & 0.000892071 & 2.765951 & 3 \\
\hline Sq. Hangseng & 2488 & 0.00029152 & 0.000903104 & 3.097866 & 1 \\
\hline Sq. Kospi & 2463 & 0.00035185 & 0.000894530 & 2.542347 & 4 \\
\hline Sq. KSE & 2449 & 0.00025872 & 0.000537625 & 2.078059 & 6 \\
\hline Sq. Nikkei & 2453 & 0.00026883 & 0.000771734 & 2.87075 & 2 \\
\hline Sq. Shanghai & 2580 & 0.00028183 & 0.000711177 & 2.523459 & 5 \\
\hline Valid N (listwise) & 2449 & & & & \\
\hline
\end{tabular}

Source: authors' estimation 
Descriptive analysis (monthly \& annual returns). In order to develop an easy understanding, these average stock returns are transformed into monthly and annual returns. It is clear from the Table 2 that KOSPI has the highest annual returns of $12.67 \%$, followed by BSE $11.61 \%$. KSE is, however, getting the least returns of $9.31 \%$ p.a., which endorses the least coefficient of variation i.e. 2.078 as shown in the previous Table 1.

Table 2. Descriptive analysis (monthly \& annual returns)

\begin{tabular}{lccc}
\hline & $\mathrm{N}$ & Mean Monthly & Mean Annual \\
\hline Sq. BSE & 2453 & 0.009676 & 0.116107 \\
\hline Sq. Hangseng & 2488 & 0.008746 & 0.104947 \\
\hline Sq. Kospi & 2463 & 0.010556 & 0.126666 \\
\hline Sq. KSE & 2449 & 0.007762 & 0.093139 \\
\hline Sq. Nikkei & 2453 & 0.008065 & 0.096779 \\
\hline Sq. Shanghai & 2580 & 0.008455 & 0.101459 \\
\hline Valid N (listwise) & 2449 & & \\
\hline
\end{tabular}

Source: authors' estimation

Correlation between average return and risk. It is a general phenomenon that volatility of any equity market always has been a positive correlation with equity returns because higher risks give higher yield. In order to conduct a formal investigation, a correlation between average return and risk is carried out, and results are shown in Table 3.

The coefficient of correlation obtained between average return and risk of squared stock returns is 0.7514 , which is considered as strong association but statistically insignificant, since $\mathrm{t}$ - calculated of 2.27 is less than $\mathrm{t}$ - critical of 2.77 . Since $\mathrm{t}-$ statistic is very close, we follow $\mathrm{p}$ - value approach i.e. $p<\alpha$, correlation is significant at $10 \%$ significance level, which is not appreciated by econometricians.

Table 3. Correlation (average return \& risk)

\begin{tabular}{lc}
\hline \multicolumn{2}{c}{ Correlation (sq. return) } \\
\hline Mean and Standard deviation \\
\hline Pearson Coefficient of Correlation & 0.7514 \\
\hline $\mathrm{t}$ Stat & 2.2776 \\
\hline $\mathrm{Df}$ & 4 \\
\hline $\mathrm{P}(\mathrm{T}<=\mathrm{t})$ one tail & 0.0425 \\
\hline $\mathrm{t}$ Critical one tail & 2.1318 \\
\hline $\mathrm{P}(\mathrm{T}<=\mathrm{t})$ two tail & 0.085 \\
\hline $\mathrm{t}$ Critical two tail & 2.7764 \\
\hline
\end{tabular}

Source: authors' estimation 
Correlation analysis. It is further analyzed from historical graph of Figure 1, every time series data of stock markets follow the significant similar pattern, thus, Pearson correlation coefficient " $r$ " has been calculated through formal examination. The results of correlation depicted that every market has positive correlation and interdependence except KSE100 and Nikkei225, which have negative but insignificant association.

All associations are not significantas shown in Table 4, KOSPIand Shanghai, and KSE and Shanghai have significant associations at 5\%, whereas, BSE and Hang Seng, Hang Seng and KOSPI, Hang Seng and Nikkei, BSE and Nikkei, KOSPIand Nikkei, Hang Seng and Shanghai, and Nikkei and Shanghai have significant association at $1 \%$. It is also important to note that high volatility trailed by high correlation. Hence, it is not viable to maintain the same investment portfolio for those investors and firms who are risk averse.

Table 4. Correlation analysis

\begin{tabular}{|c|c|c|c|c|c|c|c|}
\hline & & $\begin{array}{l}\text { sq. } \\
\text { BSE }\end{array}$ & $\begin{array}{c}\text { sq. } \\
\text { Hangseng }\end{array}$ & $\begin{array}{c}\text { sq. } \\
\text { Kospi }\end{array}$ & $\begin{array}{l}\text { sq. } \\
\text { KSE }\end{array}$ & $\begin{array}{c}\text { sq. } \\
\text { Nikkei }\end{array}$ & $\begin{array}{c}\text { sq. } \\
\text { Shanghai }\end{array}$ \\
\hline sq. BSE & $\begin{array}{l}\text { Pearson } \\
\text { Correlation } \\
\text { Sig. (2-tailed) } \\
\text { N }\end{array}$ & $\begin{array}{c}1 \\
2453\end{array}$ & & & & & \\
\hline sq. Hangseng & $\begin{array}{l}\text { Pearson } \\
\text { Correlation } \\
\text { Sig. (2-tailed) } \\
\text { N }\end{array}$ & $\begin{array}{c}\mathbf{0 . 3 0 0}^{* *} \\
0.000 \\
2453\end{array}$ & $\begin{array}{c}1 \\
2488\end{array}$ & & & & \\
\hline sq. Kospi & $\begin{array}{l}\text { Pearson } \\
\text { Correlation } \\
\text { Sig. (2-tailed) } \\
\text { N }\end{array}$ & $\begin{array}{l}0.037 \\
0.067 \\
2453\end{array}$ & $\begin{array}{c}\mathbf{0 . 0 8 6}^{* *} \\
0.000 \\
2463\end{array}$ & $\begin{array}{c}1 \\
2463\end{array}$ & & & \\
\hline sq. KSE & $\begin{array}{l}\text { Pearson } \\
\text { Correlation } \\
\text { Sig. (2-tailed) } \\
\text { N }\end{array}$ & $\begin{array}{l}0.018 \\
0.367 \\
2449\end{array}$ & $\begin{array}{l}0.025 \\
0.224 \\
2449\end{array}$ & $\begin{array}{l}0.011 \\
0.580 \\
2449\end{array}$ & $\begin{array}{c}1 \\
2449\end{array}$ & & \\
\hline sq. Nikkei & $\begin{array}{l}\text { Pearson } \\
\text { Correlation } \\
\text { Sig. (2-tailed) } \\
\text { N }\end{array}$ & $\begin{array}{c}\mathbf{0 . 0 8 4}^{* *} \\
0.000 \\
2453\end{array}$ & $\begin{array}{c}\mathbf{0 . 1 1 7}^{* *} \\
0.000 \\
2453\end{array}$ & $\begin{array}{c}\mathbf{0 . 2 0 1}^{* *} \\
0.000 \\
2453\end{array}$ & $\begin{array}{c}-0.026 \\
0.198 \\
2449\end{array}$ & $\begin{array}{c}1 \\
2453\end{array}$ & \\
\hline sq. Shanghai & $\begin{array}{l}\text { Pearson } \\
\text { Correlation } \\
\text { Sig. (2-tailed) } \\
\text { N }\end{array}$ & $\begin{array}{l}0.038 \\
0.062 \\
2453\end{array}$ & $\begin{array}{c}\mathbf{0 . 0 6 2}^{* *} \\
0.002 \\
2488\end{array}$ & $\begin{array}{c}\mathbf{0 . 0 4 3}^{*} \\
0.032 \\
2463\end{array}$ & $\begin{array}{c}\mathbf{0 . 0 4 9}^{*} \\
0.015 \\
2449\end{array}$ & $\begin{array}{c}\mathbf{0 . 0 7 7}^{* *} \\
0.000 \\
2453\end{array}$ & $\begin{array}{c}1 \\
2580\end{array}$ \\
\hline
\end{tabular}

Notes: ${ }^{*}$ significance at $1 \%,{ }^{*}$ significance at $5 \%$

Source: authors' estimation

Inferential analysis. Bartlett's (1937) test has been employed in order to run inferential analysis. The application of Bartlett's test is useful in order to check the equality of variances in $\mathrm{k}$ number of data sets. Equality of variances across the data sets is known as homogeneity of variances, analysis of variance (ANOVA) test also assumes the same notion of equality of variances across the groups, and Bartlett's test is the apparatus to confirm this assumption. 
The Bartlett's test also checks the difference among volatilities, and gives precise results whether these volatilities of stock returns are statistically significant or insignificant among equity markets.

The results of Bartlett's statistics shows the value of 84.43 , and it is greater as compared to the Chi - square critical value of 11.07 , thus it is not substantiated the null hypothesis that refers to the equality of variances for all samples data in comparison of alternative hypothesis, which states at least one pair of variances is not equal to the rest of variance of taken stock markets. It is a rule of thumb for the significance if $\alpha<\rho$, here $\alpha$ is known as the level of significant and also causes for type-I error, and $\rho$ is the probability value. From Table 5, it is noted that the value of $\rho$ is very small and approaches to zero that further validated the difference among the volatilities is significant in all stock returns of all regional stock markets.

Table 5. Inferential Analysis (Bartlett's Test)

\begin{tabular}{lc}
\hline \multicolumn{2}{c}{ Bartlett's Test } \\
\hline BSE & Variances \\
\hline Hangseng & 0.000322426 \\
\hline Kospi & 0.000291633 \\
\hline KSE & 0.00035196 \\
\hline Nikkei & 0.000258239 \\
\hline Shanghai & 0.000268879 \\
\hline B Stat & 0.000281828 \\
\hline Df & 84.43312781 \\
\hline p-value & 5 \\
\hline chi-squared Critical & 11.0705 \\
\hline
\end{tabular}

Source: authors' estimation

Econometric analysis. GARCH $(1,1)$ is applied via ML - BFGS with analytical gradient developed by Kurt (2006) as Excel add in. All three parameters $\omega, \alpha, \beta$ of GARCH (1, 1) model are significant for all markets as $\rho<0.01$ which means long run variance, $1^{\text {stl lag }}$ square returns, and trailing variance are significantly explaining the conditional variance. Furthermore, the sum of GARCH coefficients, i.e. $\omega, \alpha, \beta$ suppose to be either 1 or approaches to 1 .

Since $\alpha+\beta<$ land sum of GARCH coefficients is also less than 1, therefore, the essential conditions for the model are fulfilled. Long run average variances (LRAV) for the markets' returns are also calculated by using $\sqrt{\omega / 1-\alpha-\beta}$ ) as described by Engle (2001), which has got the highest value of $2.54 \%$ for Shanghai, which has the highest weight for trailing variance of 0.593 followed by $1.96 \%$ for KOSPI with 0.402 weights for trailing variance. For KSE100, it is the lowest i.e. $1.52 \%$ with the lowest weight of 0.209 for trailing varianceas shown in Table 6. 
Since the sum of coefficients for all market returns' is less than 1, therefore, it illustrated and required to have a mean reverting variance process across markets. As the sum of coefficients gets closer to 1, the process of mean reversion gets slower as sighted by Engle (2001). As shown in Table 6, KSE100 has the slowest mean reversion process, since, the sum of coefficients is the highest i.e. 0.9367 followed by 0.9033 for BSE, whereas, Hang Seng has the highest mean reversion process as the sum of coefficients is the least i.e. 0.6308.

Table 6. Econometric analysis (GARCH Coefficients)

\begin{tabular}{lccccc}
\hline \multicolumn{1}{c}{ Markets } & $\Omega$ & A & B & Sum of GARCH Coefficients & LRAV \\
\hline KSE & $1.46 \mathrm{E}-05$ & 0.727822 & 0.208926 & 0.936762971 & 0.01521 \\
\hline BSE & $2.69 \mathrm{E}-05$ & 0.536996 & 0.366271 & 0.903293202 & 0.016671 \\
\hline Kospi & $4.32 \mathrm{E}-05$ & 0.485393 & 0.401947 & 0.88738272 & 0.019589 \\
\hline Nikkei & $3.34 \mathrm{E}-05$ & 0.479236 & 0.390029 & 0.869297558 & 0.015983 \\
\hline Shanghai & 0.000128 & 0.208851 & 0.593686 & 0.802664482 & 0.025413 \\
\hline Hangseng & $9.52 \mathrm{E}-05$ & 0.280306 & 0.350378 & 0.630779358 & 0.016057 \\
\hline
\end{tabular}

Source: authors' estimation

Normality test and randomness. All log likelihood values are positive and significantly high as shown in Table 7. JarqueBera is used for normality test, following a joint hypothesis of skewness $=0$ and Kurtosis $=3$ (extra kurtosis is zero). As output shows $p=0$ that shows a non-normal behavior in stock returns. As far as Ljung-Box statistics is concerned, it follows the hypothesis of randomness (no autocorrelation) in data set; it is rejected for all the markets' returns since, $\mathrm{p}<0.01$, except for KSE100, which observes randomness.

Table 7. JarqueBera\&Ljung-Box statistics

\begin{tabular}{lccccc}
\hline \multicolumn{1}{c}{ Markets } & Log Likelihood & JarqueBera & p-value & Ljung-Box & p-value \\
\hline KSE & 6954.261586 & 592.671904 & 0.00 & 0.2449024 & 0.620688 \\
\hline BSE & 5413.483111 & 4318.948786 & 0.00 & 8.0330563 & 0.004593 \\
\hline Kospi & 5431.285508 & 1728.914164 & 0.00 & 28.915941 & $7.56 \mathrm{E}-08$ \\
\hline Nikkei & 5519.831209 & 4565.884822 & 0.00 & 43.771475 & $3.69 \mathrm{E}-11$ \\
\hline Shanghai & 5448.532362 & 1176.66945 & 0.00 & 13.11814 & 0.000292 \\
\hline Hangseng & 5626.849879 & 7597.045989 & 0.00 & 7.468934 & 0.006277 \\
\hline
\end{tabular}

Source: authors' estimation

\section{Discussion}

Results of the study are very much aligned with previous researches, for example French et al. (1987), reported positive and substantial relation between equity volatility and returns, whereas, Theodossiou and Lee (1995) determined positive relation, however, it was not significant between the same. Bollerslev and Wooldridge (1992) computed correlation between daily returns with conventional volatility estimators as high as $91 \%$ based on GARCH models. This is an excellent literature survey on conditional heteroskedasticity, 
which signifies this study also. Xing (2004) found that education level of investors is the reason whereby stock market volatility differs across the countries. For this purpose, he incorporated 37 countries' stock market data and applied conditional variance i.e. GARCH followed by EGARCH models. Officer (1973) obtained a relationship between standard deviation (SD) of the return on the market portfolio for non-overlapping 12 month periods with monthly stock returns.

Mean reversion phenomenon has always been an interesting topic for researchers and economists in stock returns because if stock prices trail random walk (mean reversion) then it has significant consequences for stock market efficiency and asset pricing. Thus, DeBondt and Richard (1985) have studied this phenomenon (mean reversion) first time and documented for US stock markets and specific firm data.

Chaudhuri and Yangru (2003) reported mean reversion in 17 emerging stock markets at $5 \%$ significance level against the random walk hypothesis. The 17 markets included Pakistan, India, and Korea (these markets are the part of our study as well). Our results of mean reversion are significant even at $1 \%$. Similarly, Balverset al. (2000) examined the eighteen developed stock markets, and found a mean reversion phenomenon across all eighteen equity markets, they further explained that by using mean reversion property and parametric contrarian investment strategy the stock returns can be predicted for any equity market. Since the sum of coefficients for all market returns' is less than 1 that is the prerequisite for mean reversion variance process as suggested by Engle (2001). In our research, six Asian markets follow mean reversion, however, comparatively, some are fast and some are slow. It helps forecasting future risk and returns. Categorically speaking for Karachi stock market, the highest mean reversion is observed with the coefficient of 0.9367 , followed by 0.9033 for BSE. Furthermore, these markets follow randomness as well, whereas, Hang Seng has the highest mean reversion process as the sum of coefficients is the least i.e. 0.6308. Long run average variances (LRAV) for Shanghai has the highest value of $2.54 \%$, which has the highest weight for trailing variance $=0.593$ followed by $1.96 \%$ for KOSPI with 0.402 weights for trailing variance. For KSE100, it is the lowest i.e. $1.52 \%$ with the lowest weight of 0.209 for trailing variance, it is also in line with the calculation guidance provided by Engle (2001) and developed by Kurt (2006).

Saleem (2007) calculated the stock returns by using the natural log of the ratio of stock market index as closing and opening daytimes. The descriptive analysis of our study illustrates that KOSPI has the highest average return of $0.0351 \%$, and trailed by BSE Sensex with $0.0322 \%$ average return, while KSE100 has the least returns of $0.0258 \%$. Moreover, descriptive analysis for annual returns showed that the KOSPI has again the highest annual returns $=12.67 \%$, followed by BSE $11.61 \%$. KSE is, however, getting the least returns of $9.31 \%$ p.a., which endorses the least coefficient of variation $=2.078$. Correlation analysis indicated that KOSPI and Shanghai, and KSE and Shanghai have significant associations at 5\%, whereas, BSE \& Hang Seng, Hang Seng and KOSPI, Hang Seng and Nikkei, BSE and Nikkei, KOSPI and Nikkei, Hang Seng and Shanghai, and Nikkei and Shanghai have significant association at $1 \%$. These insights are obtained for the first time in such a comparative mode. 


\section{Conclusion}

In preliminary investigation, the graphical representation of time series shows the examination of stock behaviors. The analysis shows the high correlation and heteroskedastic trend (volatility) among the stock markets in selected time period. After preliminary analysis the formal descriptive method of mean, standard deviation and coefficient of variation have been applied for measuring and ranking purposes. The results shows that KOSPI has the highest average annual return of $12.67 \%$ and followed by BSE with $11.61 \%$, whereas, KSE 100 has the least annual average returns of $9.31 \%$. The highest volatility coefficient of 3.097 has been observed in Hang Seng, followed by 2.87 in Nikkei. However, the KSE 100 observed the lowest volatility coefficient of 2.078. Bartlett's test is applied for inferential analysis to investigate whether the equality of volatility is same in each market return. The results of the inferential analysis significant even at $1 \%$ significance level; therefore, the null hypothesis is rejected.

Finally, GARCH $(1,1)$ model is applied which concludes a significant ARCH (1) and GARCH (1) effects and confirms all markets' returns are statistically significant since $\mathrm{p}<0.01$ and their Long Run Average Variances (LRAV) range from $1.52 \%$ to $2.54 \%$ for KSE100 Index and Shanghai Stock Exchange respectively. Furthermore, LRAV has a direct relation with the weight of trailing variance $(\beta)$. It also gets an evidence of autocorrelation as $\mathrm{p}<0.01$ for Ljung-Box for all markets' returns except KSE100 Index. It is finally established that the sum of GARCH coefficients for all markets' returns is less than 1, which concludes a mean reverting variance process, and it is the slowest for KSE100 index, since its sum of parameters is closer to 1 .

\section{References}

Amaert, J.; Hyfte, W. V. 2005. Long horizon mean reversion for the Brussels stock exchange: evidence for the $19^{\text {th }}$ century, SSRN Electronic Journal (April). http://dx.doi.org/10.2139/ssrn.676006

Andersen, T. G.; Bollerslev, T.; Diebold F. X.; Labys, P. 2001. The distribution of exchange rate volatility, Journal of the American Statistical Association 96(453): 42-55. http://dx.doi.org/10.1198/016214501750332965

Andreou, E.; Werker, B. J. M. 2015. Residual-based rank specification tests for AR-GARCH type models, Journal of Econometrics 185(2): 305-331. http://dx.doi.org/10.1016/j.jeconom.2014.11.001

Balli, F.; Hajhoj, H. R.; Basher, S. A.; Ghassan, H. B. 2015.An analysis of returns and volatility spillovers and their determinants in emerging Asian and Middle Eastern countries, International Review of Economics and Finance (39): 311-325.http://dx.doi.org/10.1016/j.iref.2015.04.013

Balvers, R.; Wu, Y.; Gilligand, E. 2000. Mean reversion across national stock markets and parametric contrarian investment strategies, Journal of Finance 55(2): 745-772. http://dx.doi.org/10.1111/0022-1082.00225

Bartlett, M. S. 1937. Properties of sufficiency and statistical tests, Proceedings of the Royal Statistical Society and Mathematical, Physical and Engineering Sciences 160(901): 268-282. http://dx.doi.org/10.1098/rspa.1937.0109

Batra, A. 2003. Stock return volatility persistence in India: 1973-2003, Working Paper. ICRIER, New Delhi, India. 
Bekaert, G. 1995. Market segmentation and investment barriers in emerging equity markets, The World Bank Economic Review 9(10): 75-101. http://dx.doi.org/10.1093/wber/9.1.75

Bekaert, G.; Harvey, C. R. 1995. Time-varying conditional world market integration, Journal of Finance 50(2): 403-444.http://dx.doi.org/10.1111/j.1540-6261.1995.tb04790.x

Bekaert, G.; Harvey, C. R. 1997. Emerging equity market volatility, Journal of Financial Economics 43(1): 29-77. http://dx.doi.org/10.3386/w5307

Bentes, S. R. 2015. A comparative analysis of the predictive power of implied volatility indices and GARCH forecasted volatility, Physica A: Statistical Mechanics and its Applications 424: 105-112. http://dx.doi.org/10.1016/j.physa.2015.01.020

Bollerslev, T. 1986. Generalized autoregressive conditional heteroskedasticity, Journal of Econometrics 31(3): 307-327. http://dx.doi.org/10.1016/0304-4076(86)90063-1

Bollerslev, T.; Wooldridge, J. M. 1992. Quasi-maximum likelihoood estimation and inferences in dynamic models with time varying covariances, Econometric Reviews 11(2): 143-72. http://dx.doi.org/10.1080/07474939208800229

Chaboud, A. P.; Chiquoine, B.; Hjalmarsson, E.; Loretan, M. 2008. Frequency of observation and the estimation of integrated volatility in deep and liquid financial markets, International Finance Discussion Paper No. 905. Board of Governors of the Federal Reserve System.

Chen, M. 2015. Risk-return tradeoff in Chinese stock markets: some recent evidence, International Journal of Emerging Markets 10(3): 448-473. http://dx.doi.org/10.1108/IJoEM-06-2012-0058

Choudhry, T. 1996. Stock markets volatility and the crash of 1987: evidence from six emerging markets, Journal of International Money and Finance 15(6): 969-981.

http://dx.doi.org/10.1108/IJoEM-06-2012-0058

Chaudhuri, K.; Yangru, W. 2003. Mean reversion in stock prices: evidence from emerging markets, Managerial Finance 29(10): 22-37. http://dx.doi.org/10.1108/03074350310768490

Christoffersen, P. F.; Diebold, F. X. 2006. Financial asset returns, direction-of-change forecasting, and volatility dynamics, Management Science 52(8): 1273-1287. http://dx.doi.org/10.1287/mnsc.1060.0520

Claessens, S.; Dasgupta, S.; Glen, J. 1995. Return behavior in emerging stock markets, The World Bank Economic Review 9(1): 131-151. http://dx.doi.org/10.1093/wber/9.1.131

Claessens, S.; Dasgupta, S.; Glen, J. 1998. The cross-section of stock returns: evidence from the emerging markets, Emerging Markets Quarterly 2(Winter): 4-13. http://dx.doi.org/10.1596/1813-9450-1505

Davidian, M.; Carroll, R. 1987. Variance function estimation, Journal of the American Statistical Association 82(400): 1079-1091. http://dx.doi.org/10.2307/2289384

DeBondt, W. F. M.; Richard, T. 1985. Does the stock market overreact?, Journal of Finance 40(3): 793-805. http://dx.doi.org/10.1111/j.1540-6261.1985.tb05004.x

Engle, R. 2001. GARCH 101: the use of ARCH/GARCH models in applied econometrics, Journal of Econometric Perspectives 15(4): 157-168. http://dx.doi.org/10.1257/jep.15.4.157

Engle, R.; Lee, G. J. (1999). A permanent and transitory component model of stock return volatility, in R. Engle, H. White (Eds.). Cointegration, causality, and forecasting: A festschrift in honor of Clive W. J. Granger. Oxford University Press, 475-497

Engle, R. F. 1982. Autoregressive conditional heteroskedasticity with estimates of the variance of UK inflation, Econometrica 50: 987-1008. http://dx.doi.org/10.2307/1912773

Fama, E. F. 1965. The behavior of stock-market prices, The Journal of Business 38(1): 34-105. http://dx.doi.org/10.1086/294743

French, K. R.; Schwert, G. W.; Stambaugh, R. F. 1987. Expected stock returns and volatility, Journal of Financial Economics 19: 3-29. http://dx.doi.org/10.1016/0304-405X(87)90026-2

Galbraith, J. W.; Zinde-Walsh, V.; Zhu, J. M. 2015. GARCH model estimation using estimated quadratic variation, Econometric reviews 34(6-10): 1171-1191. http://dx.doi.org/10.1080/07474938.2014.956629 
Ghysels, E.; Harvey, A.; Renault, E. 1996. Stochastic volatility, in G. Maddala, C. Rao (Eds.). Handbook of Statistics. Vol. 14. Amsterdam: Elsevier Science. http://dx.doi.org/10.1016/s0169-7161(96)14007-4

Granger, C. W. J.; White, H.; Kamstra, M. 1989. Interval forecasting: an analysis based on ARCH-quantile estimators, Journal of Econometrics 40(1): 87-96. http://dx.doi.org/10.1016/0304-4076(89)90031-6

Harvey, A.; Ruzi, E.; Sheperd, N. 1994. Multivariate stochastic variance models, Review of Economic Studies 61(2): 247-264. http://dx.doi.org/10.2307/2297980

Inoguchi, T. 2014. A call for a new Japanese foreign policy: the dilemmas of a stakeholder state, International Affairs 90(4): 943-958. http://dx.doi.org/10.1111/1468-2346.12149

Investopedia.com (2016). What is "Volatility" [online], [cited 27 August 2016]. Available from Internet http://www.investopedia.com/terms/v/volatility.asp

Jarrell, G.; Poulsen, A. 1989. The return of acquiring firms in tender offers: evidence from three decades, Financial Management 18(3): 12-19. http://dx.doi.org/10.2307/3665645

Jensen, M. C.; Ruback, R. S. 1983. The market for corporate control: the scientific evidence, Journal of Financial Economics 11(1-4): 5-50. http://dx.doi.org/10.1016/0304-405X(83)90004-1

Johnk, D. W.; Soydemir, G. 2015. Time-varying market price of risk and investor sentiment: evidence from a multivariate GARCH model, Journal of behavioral finance 16(2): 105-119. http://dx.doi.org/10.1080/15427560.2015.1034856

Kim, E. H.; Singal, V. 2000. Stock market openings: experience of emerging economies, Journal of Business 73(1): 25-66. http://dx.doi.org/10.1086/209631

Kurt, A. (2006). Excel add-in for econometric time series analysis, ARMA, GARCH, and E-GARCH [online], [cited 15 August 2013]. Available from Internet http://www.web-reg.de/garch_addin.html

Lee, S.; Ki, O. 1991.Time-varying volatilities and stock market returns: international evidence, in Ghon Rhee, Rosita Chang (Eds.). Pacific-Basin Capital Markets Research. Volume II. Amsterdam: NorthHolland.

Meghir, C.; Pistaferri, L. 2004. Income variance dynamics and heterogeneity, Econometrica 72(1): 1-32. http://dx.doi.org/10.1111/j.1468-0262.2004.00476.x

Merton, R. C. 1980. On estimating the expected return on the market: an exploratory investigation, Journal of Financial Economics 8: 323-361. http://dx.doi.org/10.1016/0304-405X(80)90007-0

Nguyen, T.; Ngo, Ch. 2014. Impacts of the US macroeconomic news on Asian stock markets, The Journal of Risk Finance 15(2): 149-179. http://dx.doi.org/10.1108/JRF-09-2013-0064

Officer, R. R. 1973. The variability of the market factor of the NYSE, Journal of Business 46(3): 434-453. http://dx.doi.org/10.1086/295551

Okičić, J. 2015. An empirical analysis of stock returns and volatility: the case of stock markets from Central and Eastern Europe, South East European Journal of Economics and Business 9(1): 7-15. http://dx.doi.org/10.2478/jeb-2014-0005

Rajwani, S.; Mukherjee, J. 2013. Is the Indian stock market cointegrated with other Asian markets?, Management Research Review 36(9): 899-918. http://dx.doi.org/10.1108/MRR-06-2012-0141

Ramirez, O. A.; Fadiga, M. 2003. Forecasting agricultural commodity prices with asymmetric error GARCH models, Journal of Agricultural and Resource Economics 28(1): 71-85.

Raza, M. A.; Arshad, I. A.; Ali, N.; Munawar, S. 2015. Empirical analysis of stock returns using symmetric and asymmetric GARH models: evidence from Karachi stock exchange, Science International 27(1): 795-801.

Reisman, G. 1999. When will the Bubble burst? School of Business and Management, Pepperdine University.

Rich, R.; Tracy, J. 2004. Uncertainty and labor contract durations, Review of Economics and Statistics 86(1): 270-287. http://dx.doi.org/10.3386/w7731 
Saleem, K. 2007. Modeling volatility and asymmetries of KSE, SSRN Electronic Journal 02/2007. http://dx.doi.org/10.2139/ssrn.964898

Salinger, M. 1992. Value event study, Review of Economics and Statistics 74(4): 671-677. http://dx.doi.org/10.2307/2109381

Schwert, G. W. 1989. Stock market volatility, Financial Analysts Journal 46(3): 23-34. http://dx.doi.org/10.2469/faj.v46.n3.23

Schwert, G. W. 1990. Stock volatility and crash of 87, Review of Financial Studies 3(1): 77-102. http://dx.doi.org/10.1093/rfs/3.1.77

Schwert, G. W. 1998. Stock market volatility: ten years after the crash, Brookings - Wharton Papers on Financial Services. Washington, DC: Brookings Institution. http://dx.doi.org/10.3386/w6381

Seth, N.; Sharma, A. K. 2015. International stock market efficiency and integration: evidences from Asian and US markets, Journal of Advances in Management Research 12(2): 88-106. http://dx.doi.org/10.1108/JAMR-07-2011-0010

Shephard, N. 1995. Statistical aspect of ARCH and stochastic volatility, in D. R. Cox, D. V. Hinkley, O. E. Barndorff-Nielson (Eds.). Time Series Models in Econometrics, Finance and Other Fields. London: Chapman \& Hall: 1-67.

Shiller, R. J. 1981. The use of volatility measures in assessing market efficiency, Journal of Finance 36(2): 291-304. http://dx.doi.org/10.3386/w0565

Shiller, R. J.; Perron, P. 1985. Testing the random walk hypothesis: powerversus frequency of observation, Economic Letters 18(4): 381-386. http://dx.doi.org/10.3386/t0045

Shin, J. 2005. Stock return and volatility in emerging stock markets, International Journal of Business and Economics 4: 31-43.

Singhania, M.; Anchalia, J. 2013. Volatility in Asian stock markets and global financial crisis, Journal of Advances in Management Research 10(3): 333-351. http://dx.doi.org/10.1108/JAMR-01-2013-0010

Snedecor, G. W.; Cochran, W. G. 1989. Statistical methods. 8th edition. Ames, Iowa: Iowa State University Press.

Summers, L. H. 1986. Does the stock market rationally reflect fundamental values?, Journal of Finance 41(3): 591-601. http://dx.doi.org/10.1111/j.1540-6261.1986.tb04519.x

Taylor, S. J.; Xu, X. 1997. The incremental volatility information in one million foreign exchange quotations, Journal of Empirical Finance 4(4): 317-340. http://dx.doi.org/10.1016/S0927-5398(97)00010-8

Theodossiou, P.; Lee, U. 1995. Relationship between volatility and expected return across international stock markets, Journal of Business Finance and Accounting 22(2): 289-300. http://dx.doi.org/10.1111/j.1468-5957.1995.tb00685.x

Wagner, H. 2007. Volatility as a stock market indicator [online], [cited 27 August 2016]. Available from Internet www.tradingonlinemarkets.com

Xing, X. 2004. Why does market volatility differ across countries? Evidence from thirty seven international markets, International Journal of Business 9(1): 83-102.

Yu, J. 2002. Forecasting volatility in New Zealand stock market, Applied Financial Economics 12(3): 192-202. http://dx.doi.org/10.1080/09603100110090118 


\section{APPENDIX}

\section{Abbreviations}

$\begin{array}{ll}\text { KSE } & \text { Karachi (Pakistan) Stock Exchange } \\ \text { BSE } & \text { Bombay (India) Stock Exchange } \\ \text { NIKKEI } & \text { Stock market index of Tokyo (Japan) Stock Exchange } \\ \text { Hang Seng } & \text { Hong Kong Stock Exchange } \\ \text { KOSPI } & \text { South Korea Stock Exchange } \\ \text { SSE } & \text { Shanghai Stock Exchange } \\ \text { ARCH } & \text { Autoregressive conditional heteroskedasticity } \\ \text { GARCH } & \text { Generalized autoregressive conditional heteroskedasticity } \\ \text { LRAV } & \text { Long run average variances } \\ \text { ARMA } & \text { Autoregressive (AR) part and a moving average (MA) } \\ \text { EGARCH } & \text { Exponential generalized autoregressive conditional heteroskedasticity } \\ \text { GJR-GARCH } & \text { Glosten-Jagannathan-Runkle GARCH } \\ \text { APARCH } & \text { Asymmetric Power ARCH }\end{array}$

Nawaz AHMAD is Visiting Professor at Department of Business Administration at Iqra University (Pakistan); He obtained his MBA \& M.Phil. (Economics) from SZABIST University, Karachi. He is also an independent researcher and Editor of a Journal for last 15 years. During his broad research career of more than 15 years, he mainly focused on macro \& microeconomics related issues of Pakistani economy, his research expertise area are macroeconomic indicators, study of stock prices and its behavior, comparison of financial security markets by using Time Series analysis models, Multivariate Regression models, and other Econometrics models. Besides, he also made a significant contribution of research for private sector employees' and Organizational related issues; he used quantitative models for these studies.

Rizwan RAHEEM AHMED is a Professor at Institute of Business Administration \& Commerce at Indus University (Pakistan); He obtained his $\mathrm{PhD}$ from Hamdard University, and MS (Economics) from SZABIST University, Karachi. He is also an independent consultant for the Pharmaceutical Industry for last several years. During his thorough research career of more than 12 years, he mainly focused on marketing strategy, Organizational performance, behavior of Stocks, money market portfolios and Liquidity market problems by using Time Series analysis models, Multivariate Regression, CFA \& EFA models. Besides, he also made a significant research in current issues related to Sales \& Marketing of local and global Pharmaceutical Industry; he used quantitative \& qualitative models for this purpose.

Jolita VVEINHARDT is a Chief Researcher at the Institute of Sports Science and Innovations of Lithuanian Sports University and Professor at the Faculty of Sport Education of Lithuanian Sports University. Her research activity is focused on mobbing in employee relations, organisational climate, nepotism as a management anomaly, values congruence, human resource management, corporate social responsibility, the knowledge-based economy. Her publications have appeared in the Journal of Business Economics and Management, Transformations in Business and Economics, Engineering economics and Problems and Perspectives in Management among others.

Dalia STREIMIKIENE is a Chief Researcher at the Institute of Sports Science and Innovations of Lithuanian Sports University. Her research activity is focused on macroeconomic environment of business, macroeconomic policies and measures, sustainable development, climate change mitigation issues and human resource management issues. She has experience in various projects and research studies dealing with sustainability assessment. 